\title{
Unequivocal Identification of 1-Phenylethyl Acetate in Clove Buds (syzygium aromaticum (L.) Merr. \& L.M. Perry) and Clove Essential Oil
}

\author{
Klaus Gassenmeier ${ }^{1, *}$, Hugo Schwager ${ }^{1}$, Eric Houben ${ }^{2}$ and Robin Clery ${ }^{1}$ \\ 1 Givaudan (Schweiz) AG, Dübendorf 8600, Switzerland; Hugo.Schwager@givaudan.com (H.S.); \\ Robin.Clery@givaudan.com (R.C.) \\ 2 Givaudan Nederland BV, GP Naarden 1411, Netherlands; Eric.Houben@givaudan.com \\ * Correspondence: klaus.gassenmeier@givaudan.com; Tel.: +41-44-824-2521 \\ Academic Editors: Theo H. Varzakas and Charalampos Proestos \\ Received: 5 May 2017; Accepted: 21 June 2017; Published: 27 June 2017
}

\begin{abstract}
The natural occurrence of 1-phenylethyl acetate (styrallyl acetate) was confirmed in commercially available dried clove buds and also in the hydrodistilled oil from clove buds. This confirms previous reports and other anecdotal evidence for its occurrence in nature.
\end{abstract}

Keywords: 1-phenylethyl acetate; styrallyl acetate; alpha methyl benzyl acetate; clove; Syzygium aromaticum; volatile composition

\section{Introduction}

1-Phenylethyl acetate (FEMA: 2684, CAS 93-92-5) is a well-known flavor constituent admitted in many countries as a flavor ingredient. Its flavor has been described as sweet and fruity, tropical, mango, woody, musty, honey like with floral powdery nuances [1]. It is available in artificial and natural versions from various suppliers, and may also be known as styrallyl acetate or alpha methyl benzyl acetate.

According to the Volatile Compounds in Food database [2], its occurrence in food is reported in avocado [3], honey [4], melon [5] and strawberry guava [6]. Other publications state its occurrence in pineapple [7] and banana [8]. Nevertheless, none of the cited publications provides sufficient evidence for the occurrence of the title compound in food, especially when the criteria of the International Organisation of the Flavour Industry-Working Group of Methods and Analysis (IOFI WGMA) recommendation [9] are considered, which require use of an authentic standard and two independent methods of identification, e.g., mass spectrum and retention index. The occurrence of 1-phenylethyl acetate (1-PA) is mentioned in steam-distilled and expressed clove bud oil by Brian Lawrence [10] and in several Cinnamonum species [11], but no analytical details are given in those publications. This has led to remaining doubts about its occurrence in nature and some analytical service labs would regard 1-PA as not yet having been identified in nature. Consequently, flavors containing 1-PA would be regarded as not natural, regardless of whether 1-PA had been obtained from a natural source or not.

Since we had prior evidence in-house of the occurrence of 1-PA in a clove essential oil (un-published results), we re-investigated clove bud concerning the occurrence of the title compound following the recommendation in [9].

\section{Materials and Methods}

Clove buds were obtained from a local retail store. Sample A: Clove buds, whole (Migros, Dübendorf, Switzerland). The exact country of origin could not be given by the supplier, but would be Madagascar, Indonesia, Sri Lanka or Comores (communication Remo Kessler, Customer 
service, M-Infoline, Zurich, Switzerland). Sample B: Clove buds, whole, organic (Coop, Volketswil, Switzerland), Origin: India and/or Sri Lanka. Sample C: Clove buds, ground (Coop, Volketswil, Switzerland), Origin: Madagascar.

1-Phenylethyl acetate, eugenol, eugenol acetate and beta-caryophyllene were obtained from Aldrich, Switzerland.

Essential oil isolation and analysis: Clove buds (Sample A; $55 \mathrm{~g}$ ) were finely ground, mixed with water $(250 \mathrm{~mL})$, placed in a round bottom flask $(500 \mathrm{~mL})$ and hydrodistilled using a Clevenger type apparatus. Distillation was conducted for $1 \mathrm{~h}$ and the oil collected in an oil receiver. The essential oil was recovered from the condenser. A dilution 1:5 in methyl tert.butyl ether was injected in the gas chromatograph (GC) with a split ratio of 1:20.

Solid Phase Micro Extraction (SPME): $0.5 \mathrm{~g}$ of clove buds were finely ground and sealed in a $20 \mathrm{~mL}$ headspace vial. The headspace in the vial was extracted by automated SPME using a CTC autosampler (Agilent, Santa Clara, CA, USA). Equilibration at $40{ }^{\circ} \mathrm{C}$ for $10 \mathrm{~min}$, then exposure of the SPME fiber (50/30 $\mu \mathrm{m}$ DCB/CAR/PDMA, Supelco; Bellafonte, PA, USA) for $10 \mathrm{~min}$. The fiber was desorbed directly in a split/splitless inlet $\left(230^{\circ} \mathrm{C}\right)$ for $30 \mathrm{~s}$ in splitless mode.

Gas Chromatography Mass Spectrometry: An Agilent Gas Chromatograph 6890 coupled to a mass selective detector (MSD) 5975B and a flame ionization detector (FID) was used. The effluent was split 1:1 between FID and MSD. Linear retention index was calculated on an alkane scale. Column: CP-WAX $60 \mathrm{~m} \times 0.32 \mathrm{~mm}$ i.d. $\times 0.25 \mu \mathrm{m}$ film thickness (Agilent, Santa Clara, CA, USA). Temperature program: from $35{ }^{\circ} \mathrm{C}$, held for $2 \mathrm{~min}$, to $250{ }^{\circ} \mathrm{C}$ at $4{ }^{\circ} \mathrm{C} / \mathrm{min}$. Carrier gas: He, linear velocity: $25 \mathrm{~cm} / \mathrm{s}$. Injection temperature: $250{ }^{\circ} \mathrm{C}$. Injection volume: $1 \mu \mathrm{L}$. Injection mode: split (20:1). FID $\left(250{ }^{\circ} \mathrm{C}\right)$. MS Interface temperature: $280^{\circ} \mathrm{C}$; MS mode: $\mathrm{EI}$ at $70 \mathrm{eV}$; Ion source temperature: $150{ }^{\circ} \mathrm{C}$; Mass range 29-250 u. Data handling was carried out using MSD Chemstation (Agilent, Santa Clara, CA, USA).

Chiral separation was conducted using a $\beta$-DEX 120 column (Sigma-Aldrich, Saint Louis, MO, USA, $30 \mathrm{~m} \times 0.25 \mathrm{~mm} \times 0.25 \mu \mathrm{m}$ film thickness, Nr. 24304a). Carrier gas was helium at $25 \mathrm{~cm} / \mathrm{s}$. Temperature program: from $60-130{ }^{\circ} \mathrm{C}$ at $2{ }^{\circ} \mathrm{C} / \mathrm{min}$ then raised to $200^{\circ} \mathrm{C}$ at $40^{\circ} \mathrm{C} / \mathrm{min}$. The enatiomeric excess was determined by integrating $\mathrm{m} / \mathrm{z} 104$ and $\mathrm{m} / \mathrm{z} 105$. For both isomers, clean mass spectra were obtained after background subtraction.

Identification: Mass spectra and retention index were compared with reference samples.

\section{Results}

Analysis of the obtained hydrodistilled oil (Sample A) revealed Eugenol (86.3\%), beta-Caryophyllene $(6.3 \%)$ and Eugenyl acetate $(4.1 \%)$ as the main constituents. For the identification of the 1-PA the relevant retention time window was screened for the occurrence of the most typical mass fragments $m / z$ 104, 122 and 164. At a retention time of $31.26 \mathrm{~min}$, the mass spectrum in Figure 1 (top) was obtained after background subtraction. It matched the mass spectrum of the reference (Figure 1, middle). The measured retention index was 1697 compared to 1694 of the authentic reference. Based on the FID signal integration, the area percent of 1-PA was estimated to be around $0.05 \%$. This was a significantly higher value compared to a previous in-house analysis, where ground clove bud was extracted and 1-PA showed a concentration of $0.0027 \%$ (internal communication). Lawrence [10] reported the sum amount of 1-PA and two other co-eluting constituents in distilled clove, and in expressed oil from Madagascar at $0.1 \%$ and $0.21 \%$, respectively, which closely matches our measured value of $0.05 \%$. 


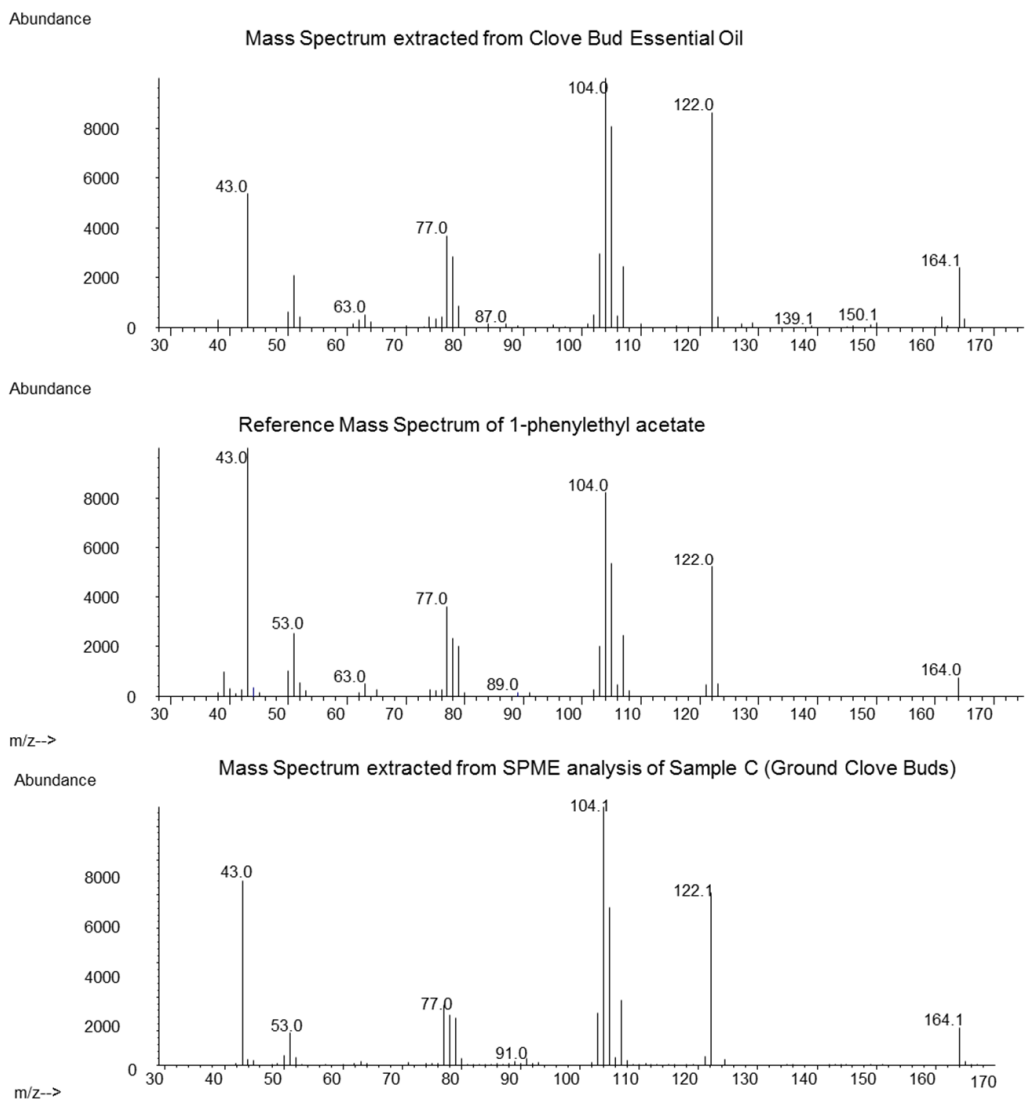

Figure 1. Comparison of the mass spectrum obtained from clove bud essential oil (top), reference mass spectrum from 1-phenylethyl acetate (1-PA) (middle) and solid phase micro extraction (SPME) of ground clove buds (sample C, bottom).

The heating during distillation may introduce chemical changes to a product, and essential oils may contain compounds not present in the native plant. To exclude this possibility, we conducted a SPME extraction of clove bud samples A, B and C. In those three samples, we could also detect the mass spectrum of 1-PA at the correct retention index (mass spectrum of 1-PA from SPME of sample $\mathrm{C}$ see Figure 1, bottom). The highest intensity was found in sample C (origin Madagascar), but no quantification was conducted.

The formation pathway of 1-phenylethyl acetate is unclear; there could be an enzymatic or chemical process. The enzymatic processes of biosynthesis often lead to products with an enantiomeric excess of one stereo isomer. To elucidate this, we conducted a chiral analysis of the 1-phenylethyl acetate. Peak identification was based on mass spectrometry and comparison to a sample of 1-PA racemate. In the essential oil obtained from clove buds, we found a significant enantiomeric excess of $62 \%$ for the first eluting enantiomer. Lacking enantiomeric pure 1-PA as reference for either of the two 1-PA enantiomers, we could not assign the configuration ( $R$ or $S$ ) of the major isomer.

\section{Discussion and Conclusions}

1-Phenyethyl acetate was unequivocally identified in clove bud essential oil and in ground clove buds. In lab-distilled essential oil obtained from clove buds, we found an enantiomeric excess of $62 \%$ of the first eluting enantiomer. On the basis of these observations, we conclude that 1-phenylethyl acetate occurs naturally in clove buds and is probably the product of enzymatic biosynthesis, and not an artifact of subsequent processing. 
Author Contributions: K.G. and H.S. conceived and designed the experiments; H.S. performed the experiments related to extraction and sample preparation; E.H. designed and executed the chiral separation; K.G. and R.C. wrote the paper.

Conflicts of Interest: The authors declare no conflict of interest.

\section{References}

1. Mosciano, G. Organoleptic characteristics of flavor materials. Perfum. Flavorist 2006, 31, 46-49.

2. Volatile Compounds in Food 16.3. Available online: http://www.vcf-online.nl/VcfHome.cfm (accessed on 8 March 2017).

3. Yamaguchi, K.; Nishimura, O.; Toda, H.; Mihara, S.; Shibamoto, T. Chemical studies on tropical fruits. In Instrumental Analysis of Foods: Recent Progress; Charalambous, G., Inglett, G., Eds.; Academic Press: San Diego, CA, USA, 1983; pp. 93-117.

4. Plutowska, B.; Chmiel, T.; Dymerski, T.; Wardencki, W. A headspace solid-phase microextraction method development and its application in the determination of volatiles in honeys by gas chromatography. Food Chem. 2011, 126, 1288-1298. [CrossRef]

5. Chaparro-Torres, L.A.; Bueso, M.C.; Fernández-Trujillo, J.P. Aroma volatiles obtained at harvest by HS-SPME/GC-MS and INDEX/MS-E-nose fingerprint discriminate climacteric behaviour in melon fruit. J. Sci. Food Agric. 2016, 96, 2352-2365. [CrossRef] [PubMed]

6. Pino, J.A.; Marbot, R.; Vázquez, C. Characterization of volatiles in strawberry guava (Psidium cattleianum Sabine) fruit. J. Agric. Food Chem. 2001, 49, 5883-5887. [CrossRef] [PubMed]

7. Steingass, C.B.; Carle, C.; Schmarr, H.G. Ripening-dependent metabolic changes in the volatiles of pineapple (Ananas comosus (L.) Merr.) fruit: I. Characterization of pineapple aroma compounds by comprehensive two-dimensional gas chromatography-mass spectrometry. Anal. Bioanal. Chem. 2015, 407, 2591-2608. [CrossRef] [PubMed]

8. Pino, J.A.; Febles, Y. Odour-active compounds in banana fruit cv. Giant Cavendish. Food Chem. 2013, 141, 795-801. [CrossRef] [PubMed]

9. Brevard, H.; Cachet, T.; Chaintreau, A.; Demyttenaere, J.C.R.; Dijkhuizen, A.; Gassenmeier, K.; Joulain, D.; Koenig, T.; Leijs, H.; Liddle, P.; et al. Statement on the identification in nature of flavouring substances, made by the Working Group on Methods of Analysis of the International Organization of the Flavour Industry (IOFI). Flavour Fragr. J. 2006, 21, 185.

10. Lawrence, B.M. Major tropical spices-Clove. In Essential Oils 1976-1977; Allured Publ Corp.: Carol Stream, IL, USA, 1979; pp. 84-145.

11. Cheng, B.Q.; Yu, X.J.; Ding, J.K.; Xu, Y.; Sun, H.D.; Ma, X.X.; Yi, Y. Cinnamomum Plant Resources and Their Aromatic Constituents; Yunnan Science and Technology Press: Yunnan, China, 2001.

(C) 2017 by the authors. Licensee MDPI, Basel, Switzerland. This article is an open access article distributed under the terms and conditions of the Creative Commons Attribution (CC BY) license (http:/ / creativecommons.org/licenses/by/4.0/). 